Original Research Paper

\title{
Mechanical synthesis of high purity Cu-In-Se alloy nanopowder as precursor for printed CISe thin film solar cells
}

\author{
Armin E. Zaghi ${ }^{\mathrm{a}, \mathrm{d}, \mathrm{h}, *}$, Marie Buffière ${ }^{\mathrm{b}, \mathrm{d}, \mathrm{h}}$, Guy Brammertz ${ }^{\mathrm{e}, \mathrm{f}}$, Maria Batuk ${ }^{\mathrm{c}}$, Nick Lenaers ${ }^{\mathrm{a}, \mathrm{d}, \mathrm{h}}$, Bas Kniknie ${ }^{\mathrm{g}}$, \\ Joke Hadermann $^{c}$, Marc Meuris ${ }^{\mathrm{e}, \mathrm{f}}$, Jef Poortmans ${ }^{\mathrm{b}, \mathrm{d}}$, Jef Vleugels ${ }^{\mathrm{a}}$ \\ a Department of Metallurgy and Materials Engineering (MTM), KU Leuven, Kasteelpark Arenberg 44, 3001 Heverlee, Belgium \\ ${ }^{\mathrm{b}}$ Department of Electrical Engineering (ESAT), KU Leuven, Kasteelpark Arenberg 10, 3001 Heverlee, Belgium \\ ${ }^{\mathrm{c}}$ Electron Microscopy for Materials Science (EMAT), University of Antwerp, Groenenborgerlaan 171, 2020 Antwerp, Belgium \\ ${ }^{\mathrm{d}}$ Imec - Partner in Solliance, Kapeldreef 75, 3001 Heverlee, Belgium \\ ${ }^{\mathrm{e}}$ Imec Division IMOMEC - Partner of Solliance, Wetenschapspark 1, 3590 Diepenbeek, Belgium \\ ${ }^{\mathrm{f}}$ Institute for Material Research (IMO), Hasselt University, Wetenschapspark 1, 3590 Diepenbeek, Belgium \\ ${ }^{\mathrm{g}}$ TNO, De Rondom 1, 5612 AP Eindhoven, The Netherlands \\ ${ }^{\mathrm{h}}$ SIM vzw, Technologiepark 935, 9052 Zwijnaarde, Belgium
}

\section{A R T I C L E I N F O}

\section{Article history:}

Received 26 January 2014

Accepted 1 March 2014

Available online 13 March 2014

\section{Keywords:}

Nanopowder

High purity ball milling

CISe

Printed solar cell

Selenization

\begin{abstract}
A B S T R A C T
Mechanical alloying and ball milling are low cost, up-scalable techniques for the preparation of high purity chalcogenide nanopowders to be used as precursor material for printing thin film solar cells. In this study, high purity copper indium selenium (Cu-In-Se) alloy nanopowders with $20-200 \mathrm{~nm}$ particle size were synthesized from macroscopic elemental $\mathrm{Cu}$, In and Se powders via mechanical alloying and planetary ball milling. The particle size distribution, morphology, composition, and purity level of the synthesized $\mathrm{Cu}$-In-Se alloy nanopowders were investigated. Thin $\mathrm{Cu}$-In-Se alloy nanopowder ink coatings, deposited on Mo-coated glass substrates by doctor blading, were converted into a CuInSe $\mathrm{C}_{2}$ semiconductor film by selenization heat treatment in Se vapor. The CuInSe $e_{2}$ film showed semiconducting band gap around $1 \mathrm{eV}$ measured by photoluminescence spectroscopy. CuInSe $\mathrm{C}_{2}$ absorber layer based thin film solar cell devices were fabricated to assess their performance. The solar cell device showed a total efficiency of $4.8 \%$, as measured on $0.25 \mathrm{~cm}^{2}$ area cell.
\end{abstract}

( 2014 The Society of Powder Technology Japan. Published by Elsevier B.V. and The Society of Powder Technology Japan. All rights reserved.

\section{Introduction}

Chalcogenide thin film solar cells are an important alternative for Si-based photovoltaic devices. Metal chalcogenide semiconductor materials such as CdTe-CdSe, CuIn ${ }_{1-x} \mathrm{Ga}_{x}(\mathrm{~S}, \mathrm{Se})_{2}$ (CIGSSe) and $\mathrm{Cu}_{2} \mathrm{ZnSn}(\mathrm{S}, \mathrm{Se})_{4}$ (CZTSSe) have been developed as efficient light absorber layers for thin film solar cell applications [1-4]. Due to the high fabrication costs of vacuum based techniques for manufacturing the chalcogenide thin film light absorbers, low cost non-vacuum fabrication techniques are being investigated. One of the

\footnotetext{
* Corresponding author at: Department of Metallurgy and Materials Engineering (MTM), KU Leuven, Kasteelpark Arenberg 44, 3001 Heverlee, Belgium. Tel.: +32 489550280; fax: +32 16321990 .

E-mail addresses: armin.zaghi@mtm.kuleuven.be, armin.zaghi@gmail.com (A. E. Zaghi), marie.buffiere@imec.be (M. Buffière), guy.brammertz@imec.be (G. Brammertz), maria.batuk@uantwerpen.be (M. Batuk), nick.lenaers@mtm. kuleuven.be (N. Lenaers), bas.kniknie@tno.nl (B. Kniknie), joke.hadermann@ uantwerpen.be (J. Hadermann), marc.meuris@imec.be (M. Meuris), jef.poortmans@ imec.be (J. Poortmans), jozef.vleugels@mtm.kuleuven.be (J. Vleugels).
}

most promising non-vacuum fabrication techniques for chalcogenide thin film PV, is based on solution processing and printing techniques [5-7]. In this approach, a thin layer of precursor ink is deposited on a substrate by a printing technique, subsequently dried to evaporate the solvents, and annealed in $\mathrm{S}, \mathrm{Se}, \mathrm{H}_{2} \mathrm{~S}$ or $\mathrm{H}_{2} \mathrm{Se}$ containing atmospheres, i.e. chalcogenization, to form a polycrystalline CIGSSe or CZTSSe chalcogenide semiconductor thin film with a typical thickness of $1-2 \mu \mathrm{m}$.

In the printing approach for fabrication of the chalcogenide solar cells, one of the main technological challenges is the preparation of the initial precursor ink suspension suitable for printing [7]. Different approaches have been developed for the formation of precursor inks, which can be categorized in two general routes, i.e., the nanoparticle dispersion route and the solution route. The nanoparticle dispersion route is based on the dispersion of precursor nanoparticles in a liquid carrier [8,9], whereas the solution route is based on a complete dissolution of chalcogenide precursors in a solvent [10-13]. The applicability of these techniques is 
evaluated by the quality of the resulting chalcogenide thin films, and the potential for up-scaling to an industrial scale process. Overall, the nanoparticle dispersion route seems to be more industrial applicable taking into account the higher freedom of choosing environmental friendly industrial solvents for high throughput printing, whereas the solution route requires hazardous solvents like hydrazine to dissolve chalcogenides [10-13].

Different approaches have been developed in recent years for the synthesis of nanoparticle precursors for chalcogenide materials, mostly focusing on chemical and solvothermal synthesis. Chemical nanoparticle synthesis is usually time consuming, relatively costly and requires sophisticated processing steps. Moreover, it is difficult to control the composition, size and morphology of the final chalcogenide nanoparticles, with a limited throughput $[14,15]$. Because of this, the applicability of the chemical route for industrial scale synthesis of chalcogenide nanoparticles is limited.

Ball milling on the other hand is conventionally used for the production of industrial dispersions and paints. This technique has been used for the synthesis of a variety of advanced nanomaterials $[16,17]$. Chalcogenide materials can also be synthesized by mechanical alloying and ball milling [18-23]. Unlike the chemical route, mechanical synthesis is fast, cost efficient, composition flexible, easy up-scalable and suitable for high throughput synthesis of powders and intermetallic alloys at an industrial scale [16]. Recently, the preparation of chalcogenide nanoparticle dispersions by colloidal wet ball milling has been reported [24-28].

The main drawback of mechanical synthesis and ball milling processes is the unavoidable contamination from the milling balls and vessel [16], whereas a high purity level is required for semiconductor and electronic materials. Therefore, the main challenge for implementing the mechanical alloying and ball milling for processing electronic and semiconductor materials is to limit the milling process contamination to an acceptable level.

In this study, high purity copper indium selenium alloy (Cu-In$\mathrm{Se}$ ) nanopowders were synthesized from elemental $\mathrm{Cu}$, In and Se powders via mechanical alloying and planetary ball milling. The particle size distribution, morphology, composition, and purity level of the synthesized $\mathrm{Cu}$-In-Se alloy nanopowders were investigated. Thin layers of $\mathrm{Cu}-\mathrm{In}-\mathrm{Se}$ alloy nanopowder were printed on Mo-coated glass substrates by doctor blade coating, followed by a drying process. The $\mathrm{Cu}-\mathrm{In}-\mathrm{Se}$ alloy nanopowder coating was converted into a CuInSe $\mathrm{C}_{2}$ semiconductor film by selenization in selenium vapor. CuInSe $\mathrm{S}_{2}$ absorber layer based thin film solar cell devices were fabricated to assess their performance.

\section{Experimental procedures}

\subsection{Mechanical synthesis of the Cu-In-Se alloy nanopowder precursor}

High purity elemental copper (99.999, 100 mesh powder, Alfa Aesar), indium (99.999, $3 \mathrm{~mm}$ shots, Chempur) and selenium (99.999, $3 \mathrm{~mm}$ shots, Alfa Aesar) were used as starting materials. Mechanical alloying was performed on a high energy planetary ball mill (PM400-AM, Retsch) at a rotational speed of 350 RPM. Elemental copper, indium and selenium with a stoichiometric $\mathrm{Cu}:$ In:Se mole ratio of 85:100:100 were loaded in yttria-stabilized zirconia (Y-TZP) ceramic milling jars, together with $10 \mathrm{~mm}$ diameter Y-TZP (Grade TZ-3Y, Tosoh) milling balls, with a ball to powder ratio of $8 / 1$. The milling jars were filled with Argon inert gas and closed. Mechanical alloying for $2 \mathrm{~h}$ resulted in a dark micrometer particle sized $\mathrm{Cu}-\mathrm{In}-\mathrm{Se}$ alloy powder with homogeneous compositions.

In order to obtain a nanometric powder of $\mathrm{Cu}-\mathrm{In}-\mathrm{Se}$ alloy, suitable for ink formation, an additional ball milling step was performed immediately after mechanical alloying. This milling step was performed on the same equipment using $3 \mathrm{~mm}$ diameter Y-TZP (Grade TZ-3Y, Tosoh) milling balls in an amine (n-butylamine) wet medium. Additional wet milling for $2-5 \mathrm{~h}$ at 350 RPM resulted in nanometer-sized powder. The particle size range could be controlled by adjusting the ball to powder ratio and the wet milling time. After the wet milling process the $\mathrm{Cu}$-In-Se alloy nanopowder was separated from amine solvent via centrifuging, and sufficiently washed with ethanol to remove the amine solvent.

\subsection{CuInSe $e_{2}$ semiconductor film formation via Cu-In-Se alloy nanopowder printing and selenization}

In order to form a dense and uniform $\mathrm{CuInSe}_{2}$ thin film via printing, a dispersion ink of the $\mathrm{Cu}-\mathrm{In}$-Se alloy nanopowder in 1,5-Pentanediol with a concentration of $250 \mathrm{mg} / \mathrm{ml}$, was printed using a doctor blade coating tool (Erichsen 409), applying approximately a $20 \mu \mathrm{m}$ wet layer thickness on a $5 \times 5 \mathrm{~cm}^{2}$ molybdenum-coated glass substrate followed by a drying process at $100^{\circ} \mathrm{C}$ in Nitrogen atmosphere. After drying, a $1-2 \mu \mathrm{m}$ thick coating of $\mathrm{Cu}$-In-Se alloy nanopowder remained on the substrate. The dried nanopowder precursor coating was annealed in a graphite box containing elemental selenium shots in Argon at $250{ }^{\circ} \mathrm{C}$ for $10 \mathrm{~min}$ and $500^{\circ} \mathrm{C}$ for $20 \mathrm{~min}$ in a home-made RTP tube furnace, resulting in a dense polycrystalline CuInSe $\mathrm{C}_{2}$ film.

\subsection{Solar cell processing}

For completing the thin film solar cell structure, a standard procedure for CIGS based solar cells was used, consisting of a $\mathrm{KCN}$ etch, chemical bath deposition of a thin n-type CdS buffer layer and AC-sputtering of $60 \mathrm{~nm}$ of intrinsic $\mathrm{ZnO}$ followed by $350 \mathrm{~nm}$ of highly Al-doped ZnO. Finally, a $50 \mathrm{~nm} \mathrm{Ni}-1 \mu \mathrm{m}$ Al finger grid pattern was evaporated through a shadow mask for top contact formation. Lateral isolation of the cells was performed by needle scribing. In this way, solar cell devices with sizes ranging from 0.25 to $1 \mathrm{~cm}^{2}$ were fabricated on $5 \times 5 \mathrm{~cm}^{2}$ substrates.

\subsection{Characterization}

The produced $\mathrm{Cu}$-In-Se alloy nanopowders were characterized by different analytical techniques. The morphology and composition of the synthesized $\mathrm{Cu}-\mathrm{In}-\mathrm{Se}$ alloy nanopowders and the final $\mathrm{CuInSe}_{2}$ film were evaluated by scanning electron microscopy (SEM, XL30-FEG, FEI), equipped with an energy dispersive X-ray analysis system (EDS, EDAX). The crystal structure of the produced $\mathrm{Cu}$-In-Se alloy nanopowders were evaluated by X-ray diffraction (XRD, $3003 \mathrm{TT}$, Seifert) with a $\mathrm{Cu} \mathrm{K} \alpha$ source. The particle size distribution after mechanical alloying and wet ball milling was measured by photon cross-correlation spectroscopy (Nanophox, Sympatec). The nanostructured nature of the synthesized $\mathrm{Cu}-\mathrm{In}-$ Se alloy nanopowders was investigated by high angle annular dark field scanning transmission electron microscopy (HAADF-STEM) and energy dispersive X-ray (EDS) analysis (TEM, Tecnai, G2, $200 \mathrm{kV}$ ). The sample for TEM investigation was prepared in the following way: the suspension of the $\mathrm{Cu}$-In-Se alloy nanopowder in ethanol was dispersed in an ultrasonic bath for $10 \mathrm{~s}$, and then several drops of the obtained suspension were deposited on a copper grid covered with a holey carbon film.

The zirconia contamination from the Y-TZP milling balls and milling vessels in the milled $\mathrm{Cu}-\mathrm{In}$-Se alloy powders was determined by ICP-AES (Inductively Coupled Plasma Atomic Emission Spectroscopy). The milled $\mathrm{Cu}$-In-Se alloy powders were dissolved in a solution of concentrated hydrochloric acid and nitric acid. The zirconium concentration in solution was determined by atomic 
emission spectroscopy using standard zirconium solutions in the same acidic media.

The band gap of the CuInSe $\mathrm{C}_{2}$ semiconductor film was measured by photoluminescence spectroscopy on a Hamamatsu C12132 near infrared compact fluorescence lifetime measurement system. The electrical characterization of the solar cell devices were performed by light and dark current-voltage $(I-V)$ measurements using an Oriel solar simulator using an AM1.5D spectrum with an illumination density of $1000 \mathrm{~W} / \mathrm{m}^{2}$ and a Keithley 2600 Sourcemeter for curve tracing, and by external quantum efficiency measurement (EQE) at room temperature using a grating monochromator-based dual-beam setup (model Bentham 605) under chopped light from halogen and xenon lamps.

\section{Results and discussion}

\subsection{Cu-In-Se alloy nanopowder precursor}

The reaction between metals and chalcogens, i.e., sulfur or selenium, are known to be extremely exothermic, and can be initiated by mechanical agitation resulting into a self-propagated reaction $[21,22]$. High energy ball milling also caused mechanical alloying of elements. As a result, after a few hours of high energy ball milling, the elemental copper, indium and selenium powders were alloyed into a homogeneous intermetallic alloy powder. Fig. 1(a and b) shows a scanning electron micrograph and particle size distribution, as measured by laser diffraction (Mastersizer Plus, Malvern) of the $\mathrm{Cu}$-In-Se alloy powder after mechanically alloying for $2 \mathrm{~h}$ at $350 \mathrm{rpm}$. The alloyed $\mathrm{Cu}-\mathrm{In}-\mathrm{Se}$ powder was micrometer sized with a major particle size distribution in the 1-10 $\mu \mathrm{m}$ range.

The alloyed $\mathrm{Cu}-\mathrm{In}-\mathrm{Se}$ powder was milled further in a wet ball milling process in n-butylamine using $3 \mathrm{~mm}$ Y-TZP milling balls. The particle size of the $\mathrm{Cu}-\mathrm{In}-\mathrm{Se}$ alloy powder reduced significantly into the nanometer size range. The particle size distribution of the $\mathrm{Cu}-\mathrm{In}-\mathrm{Se}$ alloy nanopowder can be adjusted by controlling the milling time. The SEM images and particle size distributions of the $\mathrm{Cu}$-In-Se alloy nanopowder after wet milling are presented in Fig. 1. The particle size distribution, as measured by photon cross-correlation spectroscopy (Nanophox), after $2 \mathrm{~h}$ of wet milling was in the $200-800 \mathrm{~nm}$ range, Fig. 1(c and d). After $5 \mathrm{~h}$ of wet milling, the main $\mathrm{Cu}-\mathrm{In}-\mathrm{Se}$ alloy particle size distribution is below $100 \mathrm{~nm}$ with additional particles size distribution in the 200$500 \mathrm{~nm}$ range, which are most probably agglomerates, as shown in Fig. 1(e and f).
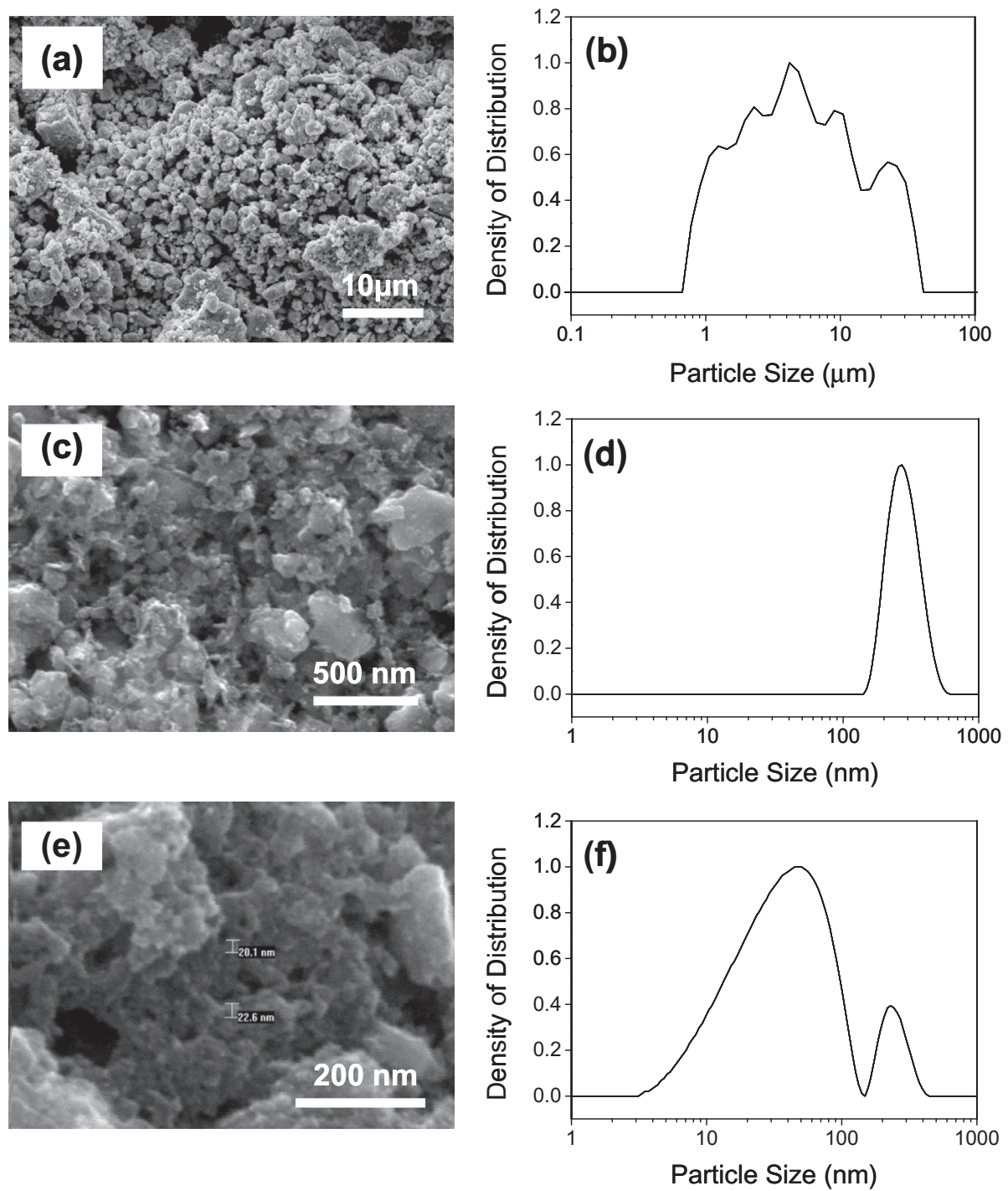

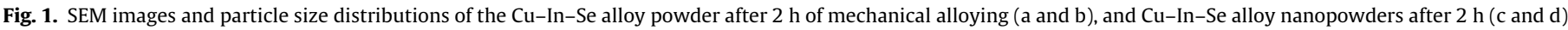
and $5 \mathrm{~h}$ (e and $\mathrm{f}$ ) of additional wet ball milling. 


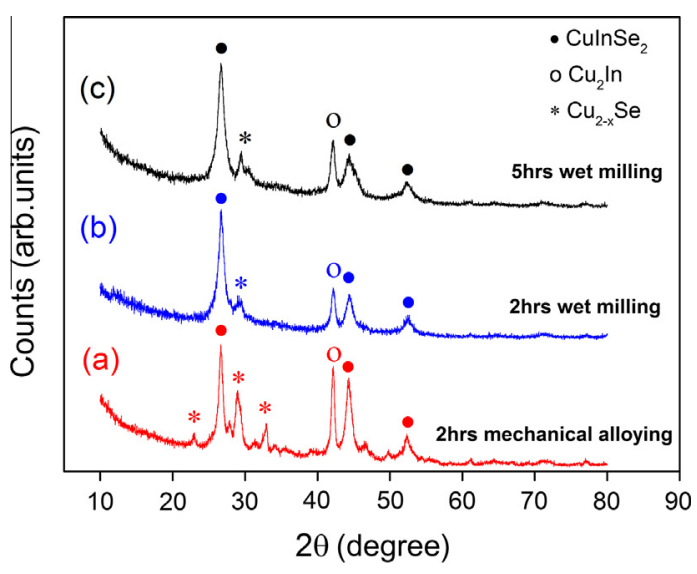

Fig. 2. XRD patterns of mechanically synthesized $\mathrm{Cu}-\mathrm{In}-\mathrm{Se}$ alloy powder after dry milling for $2 \mathrm{~h}$ at $350 \mathrm{rpm}$ (a) and $\mathrm{Cu}-\mathrm{In}-\mathrm{Se}$ alloy nanopowder after additional wet milled for $2 \mathrm{~h} \mathrm{(b)}$ and $5 \mathrm{~h} \mathrm{(c)} \mathrm{at} 350 \mathrm{rpm}$.

The XRD patterns of the Cu-In-Se alloy powders after mechanical alloying and $\mathrm{Cu}-\mathrm{In}-\mathrm{Se}$ alloy nanopowders after wet milling process are compared in Fig. 2. The broad diffraction peaks and the wide background bump in the XRD pattern, indicates that the mechanically synthesized $\mathrm{Cu}$-In-Se alloy powder and nanopowders are nanocrystalline and partially amorphous. The broad diffraction peaks that can be indexed as CuInSe 2 chalcopyrite (JCPDS card No. 40-1487), $\mathrm{Cu}_{2}$ In phase (JCPDS card No. 42-1475) and CuSe phase (JCPDS card No. 27-184), as illustrated in Fig. 2(a), imply the partial formation of nanocrystalline $\mathrm{CuInSe}_{2}$, $\mathrm{CuSe}$, and $\mathrm{Cu}_{2}$ In phases during mechanical alloying due to the fact there is not enough Se available for complete conversion to
$\mathrm{CuInSe}_{2}$. The same main diffraction peaks were present in the XRD pattern of the $\mathrm{Cu}$-In-Se alloy nanopowders after additional wet milling, although the diffraction peaks are wider, due to the further size reduction, as shown in Fig. 2(b and c). The nanostructure and phase composition of the $\mathrm{Cu}$-In-Se alloy nanopowder is advantageous for sintering and grain growth during selenization to finally form a continuous crystalline CuInSe 2 phase film.

An overview TEM image of the $\mathrm{Cu}-\mathrm{In}-\mathrm{Se}$ alloy nanopowder after $2 \mathrm{~h}$ wet milling is presented in Fig. 3 together with the high resolution (HR) TEM image and the electron diffraction (ED) pattern. The Cu-In-Se alloy nanopowder is composed of highly agglomerated crystalline and amorphous nanostructures, nanoparticles with a size of a few nanometers and rod-like nanoparticles with the length of $50-150 \mathrm{~nm}$. The ED pattern consists of rings corresponding to the polycrystalline tetragonal $\mathrm{CuInSe}_{2}$ phase (JCPDS card No. 40-1487) which corroborates the XRD data. Additional reflections on the ED pattern are attributed to the CuSe phase.

Energy dispersive spectroscopy (EDS) elemental maps of the $\mathrm{Cu}-\mathrm{In}-\mathrm{Se}$ alloy nanopowder are shown in Fig. 4. The EDS maps were generated from the intensity of the $\mathrm{Se}-\mathrm{K}, \mathrm{Cu}-\mathrm{K}$ and In-L lines indicating the heterogeneous composition of the $\mathrm{Cu}-\mathrm{In}-\mathrm{Se}$ alloy nanopowder. The EDS maps confirm that the nanoparticles are attributed to the CuInSe $e_{2}$ phase, whereas the crystalline rod-like nanoparticles are mainly composed of copper and selenium in the form of CuSe. According to HR-TEM and EDS analysis, indium-rich amorphous nanoparticles are also present.

A high purity level is essential for semiconductor material applications. In general, chalcogenide semiconductors have a higher tolerance to structural defects and impurities, due to their solid electronic structures $[29,30]$. However, the purity level and processing contamination should be carefully monitored. During
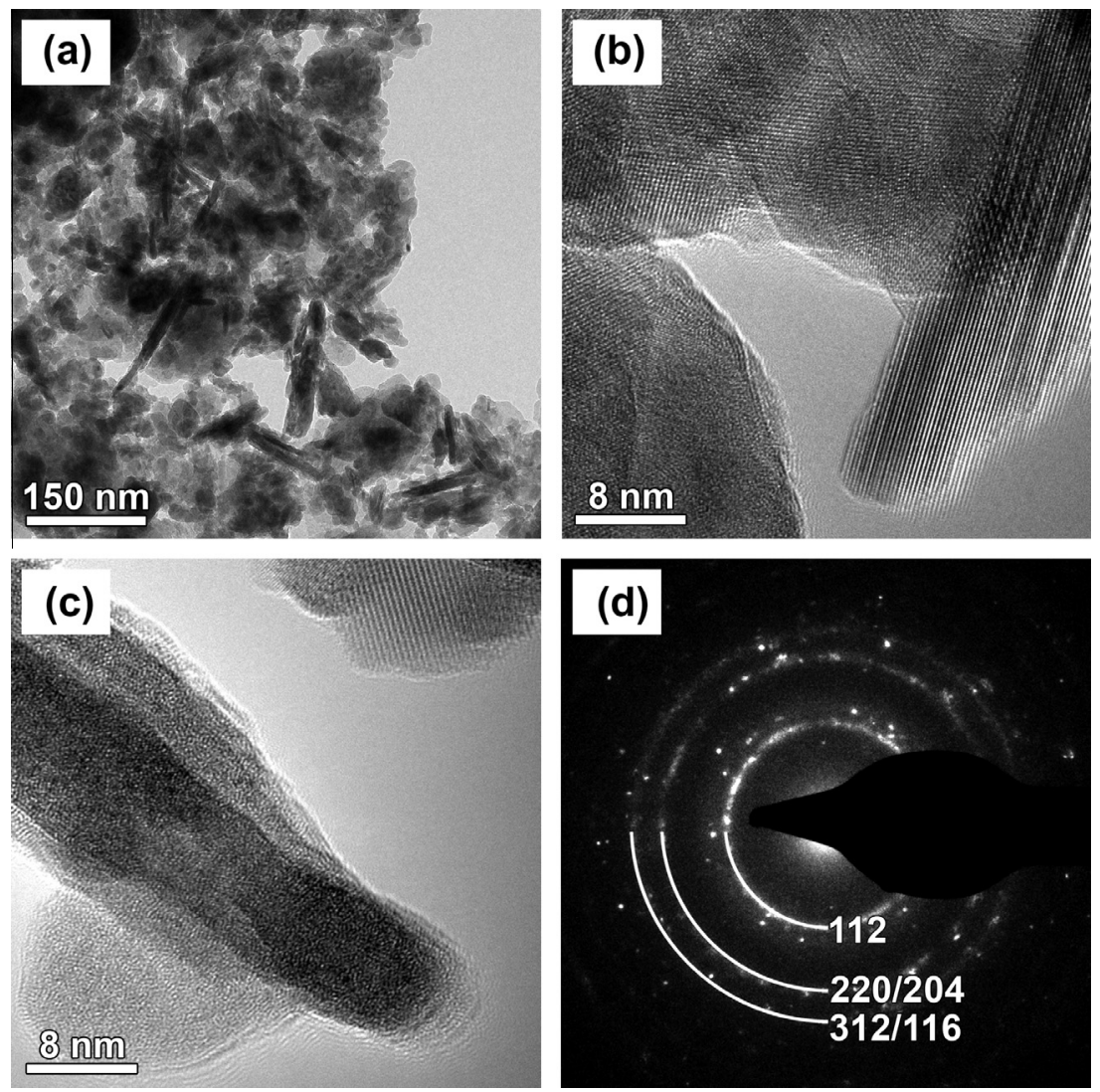

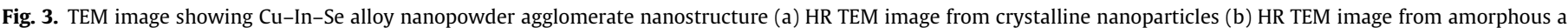

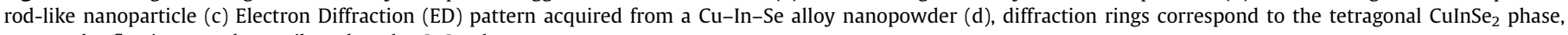
scattered reflections can be attributed to the CuSe phase. 

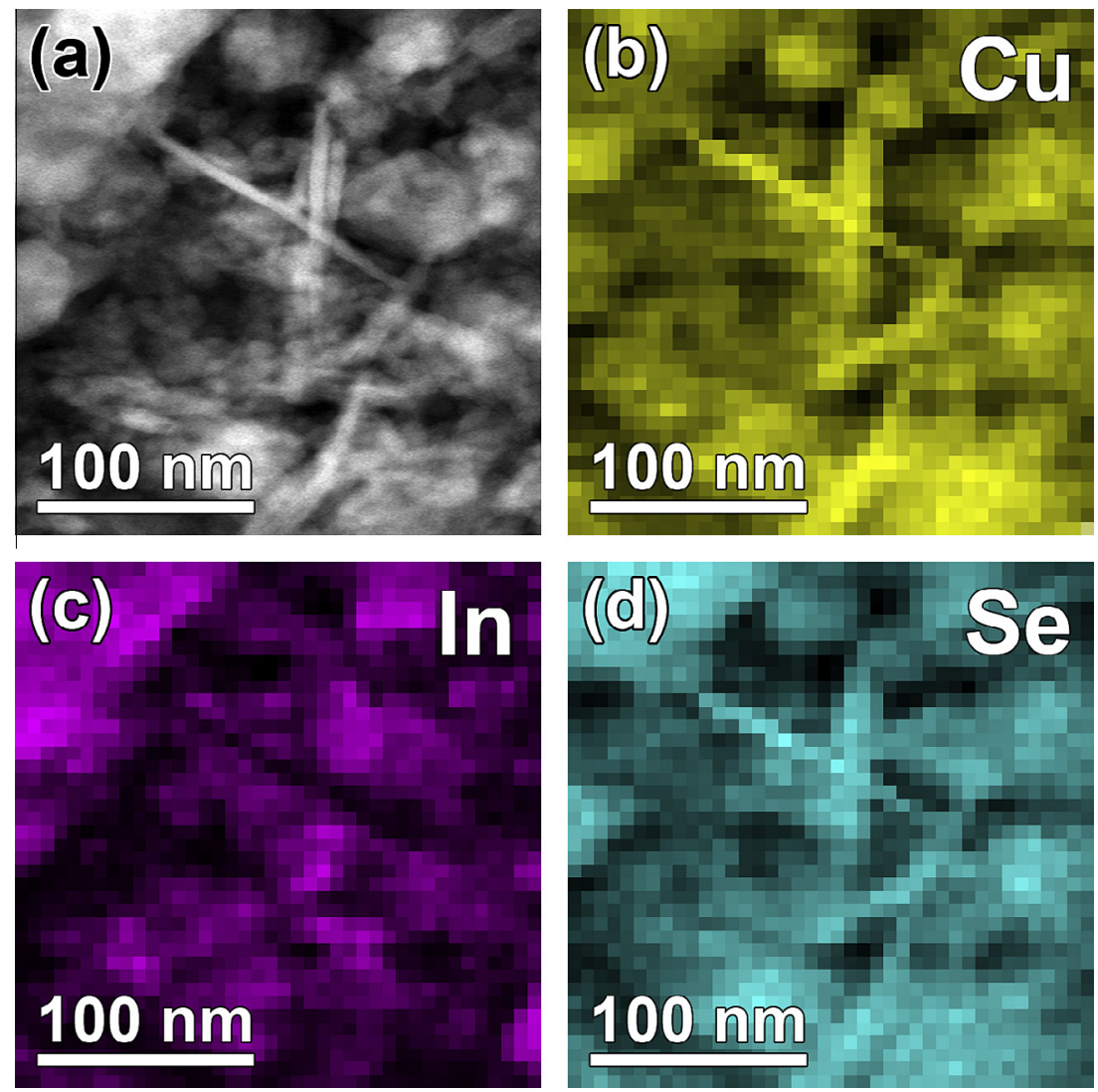

Fig. 4. HAADF-STEM image from Cu-In-Se alloy nanopowder (a) and STEM-EDS elemental maps of copper (b) indium (c) and selenium (d).

mechanical alloying and ball milling, contamination from the milling balls and milling vessel is unavoidable. The level of milling contamination however can be controlled and limited using high wear resistant Y-TZP milling balls and vessels and optimized milling parameters like ball to powder ratio, milling speed and milling time [16]. When using Y-TZP milling balls and jars, yttria-stabilised $\mathrm{ZrO}_{2}$ is the only contaminant in the produced powder.

The zirconium concentration in the different batches of mechanically alloyed and wet milled nanopowders was measured by Inductively Coupled Plasma Atomic Emission Spectroscopy (ICP-AES), as summarized in Table 1 . The concentration of zirconium in the $\mathrm{Cu}-\mathrm{In}-\mathrm{Se}$ alloy powder is around $40-70 \mathrm{ppm}$ after mechanical alloying and $100-300 \mathrm{ppm}$ in the additional wet milled $\mathrm{Cu}-\mathrm{In}-\mathrm{Se}$ alloy nanopowders. The zirconium contamination level is in the same range as reported for mechanically synthesized BSCO superconductor powders [31].

\subsection{CuInSe 2 semiconductor film}

The $\mathrm{Cu}$-In-Se alloy nanopowder that was formed after $2 \mathrm{~h}$ of the wet milling process, was dispersed in 1,5-Pentanediol solvent

Table 1

Zirconium contamination levels in mechanically alloyed $\mathrm{Cu}-\mathrm{In}-\mathrm{Se}$ powders and wet ball milled $\mathrm{Cu}-\mathrm{In}-\mathrm{Se}$ alloy nanopowders.

\begin{tabular}{llll}
\hline Milling operation & $\begin{array}{l}\text { Milling time } \\
(\mathrm{h})\end{array}$ & $\begin{array}{l}\text { Zr content } \\
(\mathrm{ppm})\end{array}$ & $\begin{array}{l}\text { Purity level } \\
(\%)\end{array}$ \\
\hline $\begin{array}{l}\text { Mechanical alloying } \\
\text { (MA) }\end{array}$ & 2 & 46 & $\sim 99.994$ \\
$\begin{array}{l}\text { Mechanical alloying } \\
\text { (MA) }\end{array}$ & 2 & 66 & $\sim 99.992$ \\
$\begin{array}{l}\text { MA + Wet milling } \\
\text { MA + Wet milling }\end{array}$ & $2+2$ & 139 & $\sim 99.985$ \\
\hline
\end{tabular}

to form an ink and doctor bladed on a molybdenum coated glass substrate. By drying of the coating, a uniform and crack-free $\mathrm{Cu}$ In-Se alloy nanopowder coating was formed, as illustrated by the SEM images taken from the surface and cross-section of the coating presented in Fig. 5 .

The $\mathrm{Cu}-\mathrm{In}-\mathrm{Se}$ alloy nanopowder coating was converted by recrystallization and sintering into a dense and continuous $\mathrm{CuInSe}_{2}$ film by a two step consecutive thermal annealing process (selenization) in Argon containing Se vapor at $250^{\circ} \mathrm{C}$ for $10 \mathrm{~min}$ and $500{ }^{\circ} \mathrm{C}$ for $20 \mathrm{~min}$.

A micrometer large grained $\mathrm{CuInSe}_{2}$ phase microstructure was formed after two step selenization in Se vapor, as shown in Fig. 6(a and b). According to the EDS measurements, the selenized CuInSe $_{2}$ film contained 24 at.\% Cu, 28 at.\% In and 48 at.\% Se, corresponding to copper poor $\mathrm{CuInSe}_{2}$ phase with an optimum $\mathrm{Cu} / \mathrm{In}$ ratio of 0.85 for p-type semiconducting properties [32]. The XRD pattern of the film after selenization shows sharp diffraction peaks corresponding to the CuInSe $e_{2}$ crystal phase (see Fig. 6(c)). The presence of sharp diffraction peaks in contrast to the as-synthesized $\mathrm{Cu}$-In-Se alloy nanopowder (Fig. 2) confirmed the recrystallization and grain growth of the $\mathrm{Cu}-\mathrm{In}-\mathrm{Se}$ alloy nanopowder into a $\mathrm{CuInSe}$ phase during selenization. Photoluminescence spectroscopy (PL) performed on the selenized CuInSe $e_{2}$ film shows a PL peak around $1 \mathrm{eV}$, corresponding to the semiconducting band gap of the CuInSe phase, as illustrated in Fig. 6(d).

\subsection{Solar cell device performance}

In order to assess the potential of the Cu-In-Se alloy nanopowder as precursor for printed CuInSe ${ }_{2}$ solar cells, SLG/Mo/CuInSe ${ }_{2} /$ $\mathrm{CdS} / \mathrm{ZnO} / \mathrm{AZO}$ photovoltaic devices were fabricated, as described in the experimental part. Fig. 7(a) shows a cross-section SEM image of the solar cell. The CuInSe $e_{2}$ film is composed of a well-sintered 

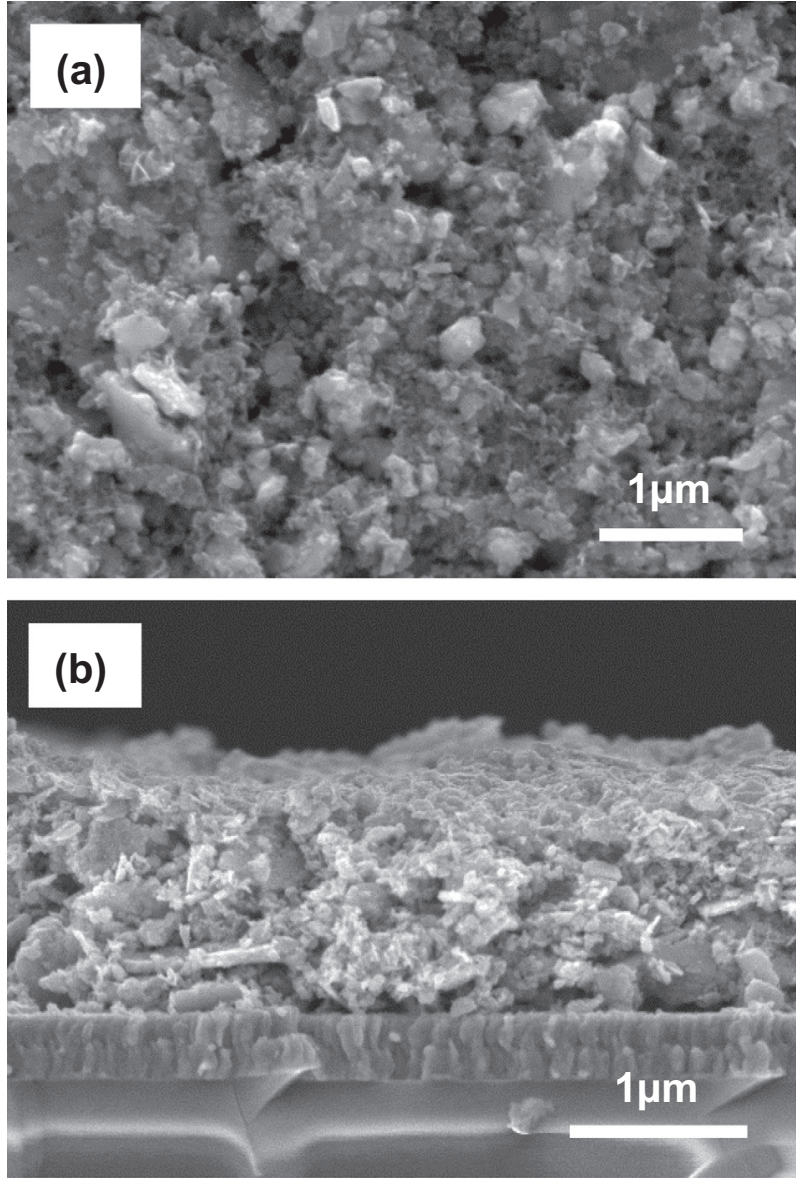

Fig. 5. Top (a) and cross-sectional (b) SEM view of the $\mathrm{Cu}-\mathrm{In}-\mathrm{Se}$ alloy nanopowder coating. top layer with relatively large grains, and a bottom layer with a smaller grain size below $200 \mathrm{~nm}$. Although both layers are converted into the CuInSe $e_{2}$ phase, the higher degree of sintering and grain growth observed in the top part of the CuInSe ${ }_{2}$ absorber film could be due to the higher Se flux at the surface of the printed film.

The electrical $J-V$ characteristic of the representative best solar cell is presented in Fig. 7(b). For this device, a total area efficiency of $4.8 \%$ was measured on $0.25 \mathrm{~cm}^{2}$ with an open circuit voltage $V_{\text {oc }}$ of $371 \mathrm{mV}$, a short circuit current density $J_{\mathrm{sc}}$ of $29.6 \mathrm{~mA} / \mathrm{cm}^{2}$ and a fill factor of $44.0 \%$. The cross-over effect, i.e., the non-superposition of the light and dark $J-V$, observed for this device has been extensively reported in literature for CuInSe $e_{2}$ based solar cells [33]. Fig. 7(c) shows the external quantum efficiency (EQE) spectrum measured on the same device. The EQE signal reaches values up to $77 \%$ in the short wavelength range, indicating good carrier collection for photo carriers generated close to the CdS interface. The decrease of the collection of the photocurrent in the long wavelength range could be explained by the bilayer structure observed in Fig. 7(a) and would indicate that the poorly sintered bottom layer is less efficient for carrier collection as compared to the top CuInSe $e_{2}$ layer due to a larger amount of defects at the free surface of the grains. Further investigation is currently in progress to verify this hypothesis. The $J_{\text {sc }}$ extracted from the integration of the EQE signal is slightly lower than the one measured by $J-V$ analysis, most probably due to the inhomogeneous distribution of the current over the area of the cell. The derivative of the EQE at the long wavelength range indicates a value of the $\mathrm{CuInSe}_{2}$ band gap estimated around $1.03 \mathrm{eV}$, which is in good agreement with the PL measurements. Finally, the very low intensity of optical interference losses as compared to a standard CuInSe $\mathrm{C}_{2}$ solar cell can be explained by the high average roughness of the printed CuInSe absorber layer. In conclusion, the $\mathrm{Cu}-\mathrm{In}-\mathrm{Se}$ alloy nanopowder is a very promising precursor for the manufacturing of printed CuIn$\mathrm{Se}_{2}$ solar cells.
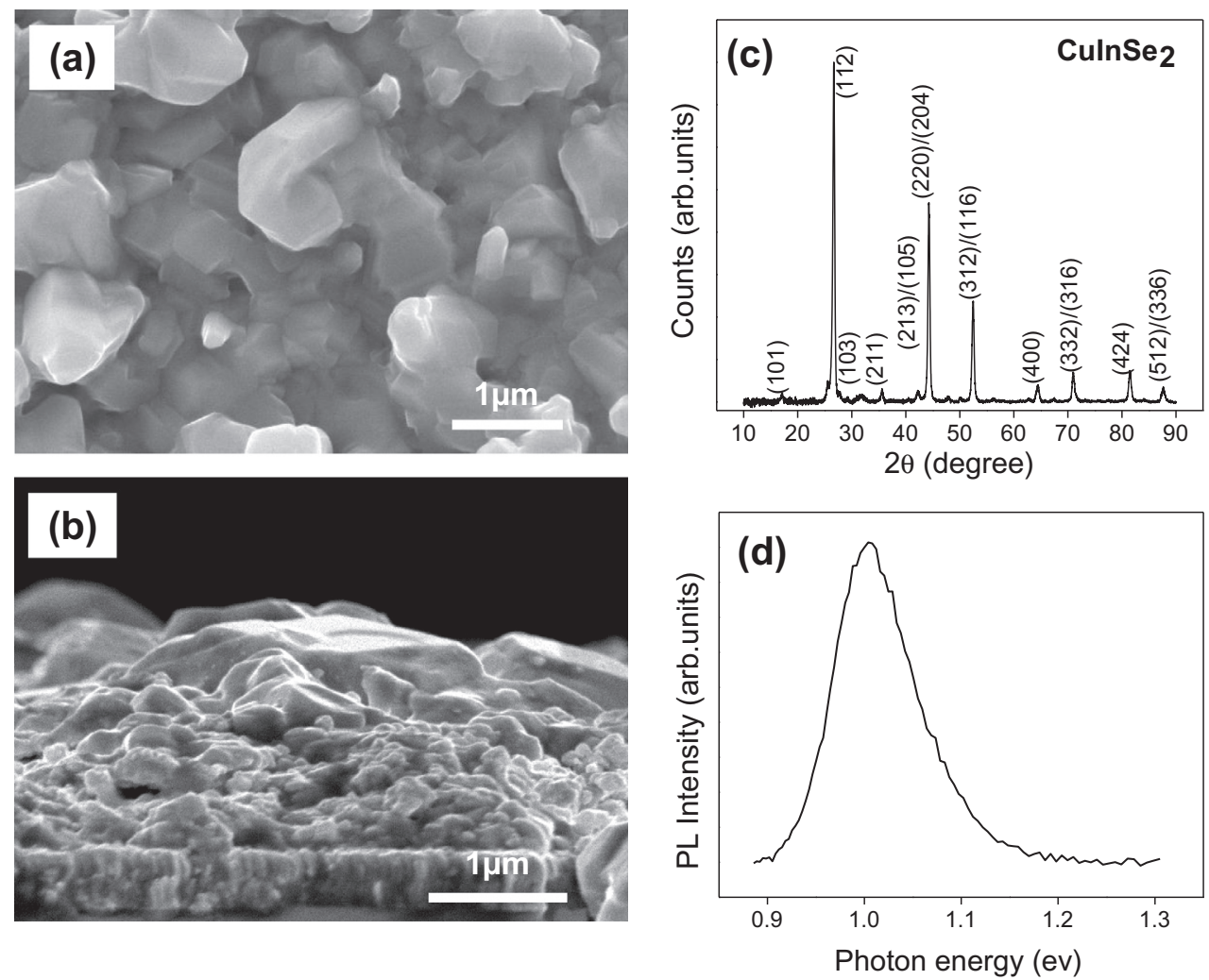

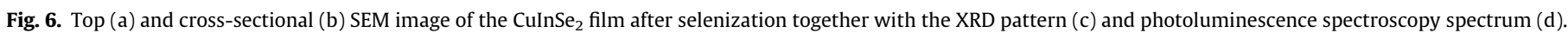



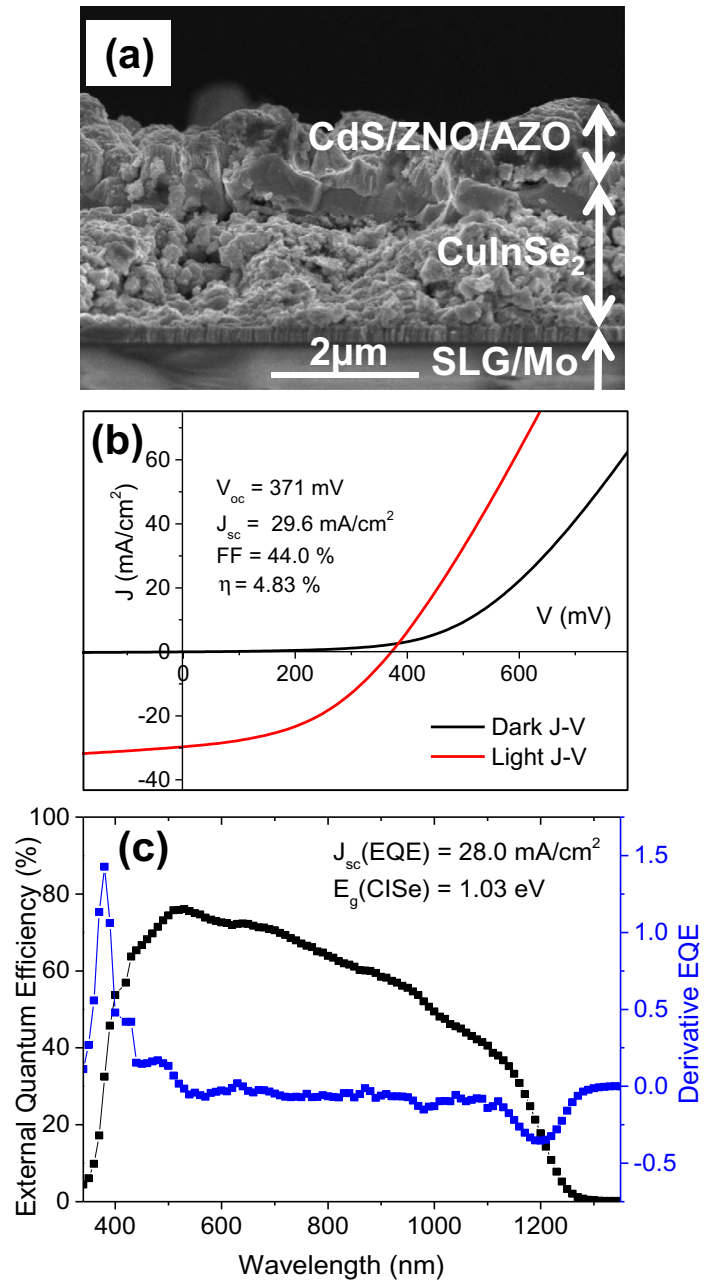

Fig. 7. Cross-sectional SEM image of the $\mathrm{SLG} / \mathrm{Mo} / \mathrm{CuInSe}_{2} / \mathrm{CdS} / \mathrm{ZnO} / \mathrm{AZO}$ solar cell, with the printed based CuInSe ${ }_{2}$ absorber layer (a) current-voltage curve of the device under dark and light conditions (b) and external quantum efficiency (EQE) of the device as function of the wavelength (c)

\section{Conclusions}

Copper indium selenium ( $\mathrm{Cu}$-In-Se) alloy was synthesized from elemental powders via mechanical alloying. Additional planetary wet ball milling in an amine solvent allowed to reduce the particle size of the $\mathrm{Cu}$-In-Se alloy powder into the nanometer size range. The zirconium contamination from the zirconia milling ball/jar based process to obtain $\mathrm{Cu}$-In-Se alloy nanopowder was determined to be below $250 \mathrm{ppm}$. The milled $\mathrm{Cu}-\mathrm{In}-\mathrm{Se}$ alloy nanopowder, composed of a mixture of amorphous and nanocrystalline CuInSe ${ }_{2}$, CuSe and $\mathrm{In}_{2}$ Se phases, transformed into a single phase polycrystalline $\mathrm{CuInSe}_{2}$ film during the selenization process. A $\mathrm{CuInSe}_{2}$ semiconductor film was prepared by doctor blade coating and selenization of the $\mathrm{Cu}$-In-Se alloy nanopowder. Finally a solar cell device was fabricated from the prepared $\mathrm{CuInSe}_{2}$ semiconductor film as light absorber layer with a standard cell structure for chalcogenide thin film solar. The solar cell device showed a total area efficiency of $4.8 \%$, as measured on $0.25 \mathrm{~cm}^{2}$ area with fill factor of $44.0 \%$. Altogether, it can be concluded that combined mechanical alloying and ball milling of elemental powders can be used as a fast, up-scalable, low cost technique for the preparation of high purity chalcogenide nanopowders for printing thin film PV applications.

\section{Acknowledgements}

This work is supported by the 'Strategic Initiative Materials' in Flanders (SIM) and the Institute for Innovation through Science and Technology in Flanders (IWT) under the Solution based Processing of Photovoltaic Modules (SoPPoM) program. Hamamatsu Photonics is acknowledged for providing the time resolved photoluminescence measurement system.

\section{References}

[1] B.J. Stanbery, Copper indium selenides and related materials for photovoltaic devices, Crit. Rev. Solid State Mater. Sci. 27 (2) (2002) 73-117.

[2] M.A. Green, Thin-film solar cells: review of materials, technologies and commercial status, J. Mater. Sci.: Mater. Electron. 18 (S1) (2007) 15-19.

[3] A.A. Rockett, Current status and opportunities in chalcopyrite solar cells, Curr. Opin. Solid State Mater. Sci. 14 (6) (2010) 143-148.

[4] A. Jager-Waldau, Progress in chalcopyrite compound semiconductor research for photovoltaic applications and transfer of results into actual solar cell production, Sol. Energy Mater. Sol. Cells 95 (6) (2011) 1509-1517.

[5] M. Kaelin, D. Rudmann, A.N. Tiwari, Low cost processing of CIGS thin film solar cells, Sol. Energy 77 (6) (2004) 749-756.

[6] C.J. Hibberd, E. Chassaing, W. Liu, D.B. Mitzi, D. Lincot, A.N. Tiwari, Non vacuum methods for formation of $\mathrm{Cu}(\mathrm{In}, \mathrm{Ga})(\mathrm{Se}, \mathrm{S})_{2}$ thin film photovoltaic absorbers, Prog. Photovoltaics Res. Appl. 18 (6) (2010) 434-452.

[7] D. Lee, K. Yong, Non vacuum deposition of CIGS absorber films for low-cos thin film solar cells, Korean J. Chem. Eng. 30 (7) (2013) 1347-1358.

[8] Q. Guo, G.M. Ford, W.-C. Yang, B.C. Walker, E.A. Stach, H.W. Hillhouse, R Agrawal, Fabrication of $7.2 \%$ efficient CZTSSe solar cells using CZTS nanocrystals, J. Am. Chem. Soc. 132 (49) (2010) 17384-17386.

[9] O. Guo, G.M. Ford, R. Agrawal, H.W. Hillhouse, Ink formulation and lowtemperature incorporation of sodium to yield $12 \%$ efficient $\mathrm{Cu}(\mathrm{In}, \mathrm{Ga})(\mathrm{S}, \mathrm{Se})_{2}$ solar cells from sulfide nanocrystal inks, Prog. Photovoltaics 21 (2013) 64-71.

[10] A. Uhl, C. Fella, A. Chirilă, Non vacuum deposition of Cu (In, Ga)Se 2 absorbe layers from binder free, alcohol solutions, Prog. Photovoltaics Res. Appl. (2012) 526-533.

[11] D.B. Mitzi, Solution processing of chalcogenide semiconductors via dimensional reduction, Adv. Mater. 21 (31) (2009) 3141-3158.

[12] T. Todorov, O. Gunawan, Solution processed $\mathrm{Cu}$ (In, Ga)(S, Se) 2 absorber yielding a 15.2\% efficient solar cell, Prog. Photovoltaics Res. Appl. 10 (2013).

[13] T.K. Todorov, J. Tang, S. Bag, O. Gunawan, T. Gokmen, Y. Zhu, D.B. Mitzi, Beyond

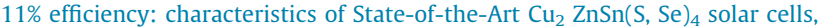
Adv. Energy Mater. 3 (1) (2013) 34-38.

[14] M.G. Panthani, V. Akhavan, B. Goodfellow, J.P. Schmidtke, L. Dunn, A. Dodabalapur, P.F. Barbara, B.A. Korgel, Synthesis of CuInS ${ }_{2}, \mathrm{CuInSe}_{2}$, and $\mathrm{Cu}(\mathrm{InxGa} 1-\mathrm{x}) \mathrm{Se}_{2}$ (CIGS) nanocrystal 'Inks' for printable photovoltaics, J. Am. Chem. Soc. 2 (7) (2008) 16770-16777.

[15] D. Aldakov, A. Lefrançois, P. Reiss, Ternary and quaternary metal chalcogenide nanocrystals: synthesis, properties and applications, J. Mater. Chem. C 1 (24) (2013) 3756.

[16] C. Suryanarayana, Mechanical alloying and milling, Prog. Mater Sci. 46 (1-2) (2001) 1-184.

[17] C. Suryanarayana, N. Al-Aqeeli, Mechanically alloyed nanocomposites, Prog. Mater Sci. 58 (4) (2013) 383-502.

[18] C. Suryanarayana, E. Ivanov, R. Nou, M.A. Contreras, J.J. Moore, Synthesis and processing of a Cu-In-Ga-Se sputtering target, Thin Solid Films 332 (1998) 340-344.

[19] C. Suryanarayana, S. Yoo, J. Groza, Consolidation of mechanically alloyed CuIn-Ga-Se powders, J. Mater. Sci. Lett. 20 (2001) 2179-2181.

[20] T. Wada, H. Kinoshita, S. Kawata, Preparation of chalcopyrite-type CuInSe $\mathrm{S}_{2}$ by non-heating process, Thin Solid Films 431-432 (2003) 11-15.

[21] T. Wada, H. Kinoshita, Rapid exothermic synthesis of chalcopyrite-type CuInSe $_{2}$, J. Phys. Chem. Solids 66 (11) (2005) 1987-1989.

[22] T. Wada, H. Kinoshita, Preparation of $\operatorname{CuIn}(\mathrm{S}, \mathrm{Se})_{2}$ by mechanochemical process, Thin Solid Films 480-481 (2005) 92-94.

[23] T. Wada, Y. Matsuo, S. Nomura, Y. Nakamura, A. Miyamura, Y. Chiba, A. Yamada, M. Konagai, Fabrication of $\mathrm{Cu}(\mathrm{In}, \mathrm{Ga}) \mathrm{Se}_{2}$ thin films by a combination of mechanochemical and screen-printing/sintering processes, Phys. Status Solidi (a) 203 (11) (2006) 2593-2597.

[24] C.P. Liu, C.L. Chuang, Fabrication of copper indium gallium diselenide absorber layer by quaternary alloy nanoparticles for solar cell applications, Sol. Energy 86 (9) (2012) 2795-2801.

[25] J.-H. Chung, S.-J. Kim, Colloidal precursors from 'ball-milling in liquid medium' process for CuInSe 2 thin film, Bull. Korean Chem. Soc. 31 (9) (2010) 2695 2697.

[26] C.P. Liu, C.L. Chuang, Fabrication of CIGS nanoparticle-ink using ball milling technology for applied in CIGS thin films solar cell, Powder Technol. 229 (2012) 78-83.

[27] Y. Liu, D. Kong, H. You, C. Zhao, J. Li, J. Brugger, Fabrication of Cu(In, Ga)Se 2 thin films from nanoparticles by non vacuum mechanochemical method and rapid thermal annealing process, ECS Solid State Lett. 1 (2) (2012) P26-P28. 
[28] B.-G. Song, J.H. Jung, G.-N. Bae, H.-H. Park, J.-K. Park, S.-H. Cho, Preparation of monolithic $\mathrm{Cu}$ In0.7Ga0.3Se 2 nanopowders and subsequent fabrication of sintered CIGS films, J. Nanosci. Nanotechnol. 13 (9) (2013) 6042-6051.

[29] S. Chen, X. Gong, A. Walsh, S.-H. Wei, Electronic structure and stability of quaternary chalcogenide semiconductors derived from cation crosssubstitution of II-VI and I-III-VI2 compounds, Phys. Rev. B 79 (16) (2009) 165211.

[30] J. Guillemoles, The puzzle of $\mathrm{Cu}$ (In, Ga)Se 2 (CIGS) solar cells stability, Thin Solid Films 404 (2002) 405-409.
[31] M. Yavuz, H. Maeda, L. Vance, Effect of ball milling materials and methods on powder processing of Bi2223 superconductors, Supercond. Sci. Technol. (1998) 1153-1159.

[32] D. Lee, L. Larina, Effect of Cu content on the photovoltaic properties of Cu (In, Ga) $\mathrm{Se}_{2}$ solar cells prepared by the evaporation of binary selenide sources, Electron. Mater. Lett. 4 (1) (2008) 13-18.

[33] A. Luque, S. Hegedus, Handbook of Photovoltaic Science and Engineering, John Wiley \& Sons, 2003, p. 593. 